Journalology

\section{Unfinished business}

\section{B Pless}

\section{Topical issues for discussion and action}

B eing an editor is both a privilege and a thankless task. One of the privileges is the opportunity, through editorials, to express somewhat personal views in a relatively unrestricted manner. A guest editor or I write and sign all editorials in Injury Prevention; in other journals editorials are written collectively while others have few or no editorials. Personally, I treasure the opportunity to write these little essays because I hope they may influence the thinking and actions of some readers. Some of my editorials have dealt with basic journalrelated topics, ${ }^{1}$ others have discussed papers in that issue ${ }^{2}$ and occasionally these editorials have addressed personal thoughts such as the need to thank mentors and colleagues before they die. ${ }^{3}$ The present editorial highlights a few problems on a long list of items that requires more discussion and then some action. They represent "unfinished business".

\section{THE ROLE OF PUBLISHING}

For much of my life as a researcher I had the naïve notion that doing a good study and getting it published in a good journal was a major step towards enhancing prevention. Over the years I've come to realize that doing so is actually quite a small step in that direction. Hence, the first item of unfinished business is finding ways to make publications a stronger element in achieving our goals. I doubt if anyone has any simple solutions but I expect part of the answer will included equal elements of attracting the media and other advocacy strategies.

I don't want to be misunderstood: To say that having a paper published does not achieve the ultimate objective is not to say that publications are of little or no value. Journals exist to record scientific achievements, and whether they do so in print or electronically these achievements are the building block on which all else is constructed. Although undoubtedly some policy decisions and programs are built with little evidence, without published evidence they are not likely to survive. The reverse is also true: when solid evidence has been published it is not likely to be ignored indefinitely. Clearly, journals have a critical place in the complex, tough process of implementing the changes needed to prevent injuries.

\section{SCIENTIFIC CHALLENGES}

In the field of injury prevention there is much unfinished scientific business that needs attention. Over the years we have touched on some of these in papers, editorials or commentaries. The list is so long that I will only offer a few examples. One issue that has made little progress is finding better ways to measure exposure. If exposure cannot be measured or measured well, then only limited conclusions can be drawn about what appear to be risk factors that need to be modified. Another example is shedding light on why males are so often at so much greater risk of injury. An early commentary ${ }^{4}$ addressed this question, but remarkably little of what we have published subsequently has made us much the wiser. These topics and many others deserve far more attention and likely will require the assistance of people from other fields, such as engineers and behavioral scientists.

\section{IMPLICATIONS OR NOT?}

We need to resolve the debate over whether it is appropriate to encourage authors to speculate about implications for prevention that arise from their findings. I understand the views of reviewers and fellow editors who side with Cummings ${ }^{5}$ in his reasons for opposing this practice, especially when it comes to policy implications. But, I maintain that a journal called Injury Prevention should focus on prevention and that the papers we publish should lie somewhere on the path to that goal (besides, "implications" seems a reasonably broad and vague term). This bit of business remains to be settled. It sets the tone for the nature of the journal.

From the outset I have tried to steer a course between publishing solid scientific material and keeping the needs of less scientifically inclined readers in mind. The latter are interested in what works, how to do it, when and where and may have little tolerance for scientific niceties. Conversely, it would be a simple matter to tell reviewers that good science alone is the benchmark of this journal. With the amount of material we are now receiving there would be no difficulty publishing a far more hard-nosed journal. What editors and readers must decide is whether doing so will best serve the field.

\section{RAISING THE PROFILE}

The most important item of unfinished business remains finding ways to raise the profile of injuries as a problem worthy of the attention of policy makers around the world. As I noted in a recent editorial, ${ }^{6}$ this has not yet happened in Canada nor has it in most other countries, developed or not. Even in the U.S. with its enviable National Centre, the situation remains far from optimal. A good journal may help, but I am increasingly convinced that the solution to profile-raising lies far more with attracting and harnessing the media.

For example, to the best of my knowledge there was remarkably little media coverage of the recent UNICEF report ${ }^{7}$ in Canada. The same may be true in other countries. The report showed that Canada has far to go if it wishes to achieve what is achievable with respect to the health and safety of its children. Of the 21 rich countries surveyed, on this measure Canada ranked 13th; the UK 12th and the US 21 st. Along with my countrymen I am guilty of not using my media contacts to expose this embarrassing finding-I did not even write my customary letter to the editor of our city newspaper. This was an unparalleled opportunity to raise our profile and most of us failed.

\section{JOURNALS OF THE FUTURE}

There are also outstanding challenges related to journals themselves. SafetyLit ${ }^{8}$ monitors 2600 journals in this field. ${ }^{9}$ A guide to those that are the most useful for most readers may be the number of papers selected as shown in SafetyLit's "journals list". When these numbers take account of the total selection period, we see yearly averages with Injury Prevention at the top of the list followed by Child Abuse and Neglect, Accident Analysis and Prevention and Safety Science. Of the top 20 less than half are all-age, all-injury general journals. Journals that are comprehensive and inclusive seem more likely to provide readers with fresh ideas than those that are narrowly focused. But if the goal is to stay current, do readers need to read a dozen or more journals?

One answer is to not bother with journals as such and to rely on web searches. Even this is not easy, however: 
As Lawrence will reveal in a forthcoming paper, to be exhaustive, searches of at least two databases will be needed. ${ }^{10}$ Another answer is to persuade our competitors to drop out and leave the field exclusively to Injury Prevention. Not a bad idea, but not too likely. More promising is the prospect of non-profit journals like this one forming alliances with its cousins, at least at the level of on-line publication. Watch this space closely.

\section{PEER REVIEW AND OPEN ACCESS}

Finally, I would be remiss to conclude an editorial entitled unfinished business without some reference to the hottest topic most editors struggle with-peer review, and its cousin, open-access publishing. ${ }^{10}$ Several studies in the BMJ and elsewhere have examined peer review, revealing many imperfections. ${ }^{11}{ }^{12}$ In spite of these findings, I remain a believer. For all its warts, peer review serves a variety of goals reasonably well. But I am convinced that we must improve the process in this journal and elsewhere. Does that mean adopting the open access argument that web viewers will prove to be the best judges of the worthiness of a paper $?^{13}$ For the present, I think not but the idea is intriguing.

The moral argument of the open-access movement is compelling: that all publicly funded research should be freely available to all. The potentially cataclysmic effects of this movement on scientific publishing is an element of new business that all future editors will need to address.

Injury Prevention 2007;13:145-146.

doi: 10.1136/ip.2007.016170

Correspondence to: Professor I B Pless, Editor; barry. pless:mcgill.ca

\section{REFERENCES}

1 Pless B. Mixed blessings: an Impact Factor. Inj Prev 2005; 11:194.

2 Pless B. In this issue: the editor's two cents. Inj Prev 2001;7:258-9.
3 Pless B. Mentoring and momenti: on timely thanks. Inj Prev 2001;7:169-70.

4 Udry JR. Why are males injured more than females? Ini Prev 1998;4:94-5.

5 Cummings $\mathbf{P}$. Policy recommendations in the discussion section of a research article. Inj Prev 2007; 13:4-5.

6 Pless IB. A chronology of failed advocacy and frustration. Ini Prev 2007; 13:73-4.

7 UNICEF. Child poverty in perspective: an overview of child well-being in rich countries, Innocenti Report Card 7. Florence, Italy: UNICEF Research Centre, 2007, Available at http://unicef-icdc.org/ publications/ (accessed May 2007).

8 SafetyLit. http://www.safetylit.org/about.htm (accessed May 2007).

9 Lawrence D. Using online databases to find peerreviewed journal articles on injury prevention and safety promotion research: a study of textword queries by SafetyLit users. Inj Prev 2007. In press.

10 Geist M. Open access: reshaping the rules of research. Toronto Star, 26 February 2007. Available at http://www.thestar.com/article/ 185609 (accessed May 2007).

11 Goldbeck-Wood S. Evidence on peer review: scientific quality control or smokescreen? BMJ 1999:318:44-5

12 van Rooyen S, Godlee F, Evans S, et al. Effect of open peer review on quality of reviews and on reviewers' recommendations: a randomized trial. BMJ 1999;318:23-7.

13 Falagas ME. Peer-review in open-access scientific journals. Open Medicine 2007;1:E49-51.
Why such measures are resisted even after this massacre is the US way of addressing gun control. As an editorial in the New York Times (April 2007) noted: "We might ask why Virginia's Legislature has decided to protect some of its shadier gun dealers from being unmasked. But, unfortunately, we already know the answer: more craven service to the allpowerful gun lobby." The editorial concludes, "The horror of tens of thousands of annual gun deaths will be compounded if the new crop of presidential candidates manages to duck an issue that more than 200 mayors, led by Mr Bloomberg, are fighting from the trenches."

Make that 200 mayors, too few researchers, and at least one editor.

Injury Prevention 2007;13:146.

doi: 10.1136/ip.2007.edjune07

Correspondence to: Professor I B Pless, Editor; barry.pless@mcgill.ca

\section{REFERENCES}

1 Wintemute G. Gun shows across a multistate American gun market: observational evidence of the effects of regulatory policies. Inj Prev 2007;13:150-5.

2 Editorial. The mayor strikes a nerve, The New York Times, 12 May 2007.Available at hitp:// www.nytimes.com/2007/05/12/opinion/ 12sat3.html?_r= 1\&oref = slogin (accessed May 2007). 